\title{
Study on Construction Technology of Drainage Prestressed Pipe Pile for Foundation Composed of Alternative Soft and Hard Soil Layers

\author{
Xin-Quan WANG ${ }^{1, a}$, Yun-Liang CUI ${ }^{1, b}$, Shi-Min ZHANG ${ }^{1, c}$, Xin-De WEN ${ }^{2, d}$, \\ Ling-Qian SUN ${ }^{2, d}$
}

${ }^{1}$ Department of Civil Engineering, Zhejiang University City College, Hangzhou 310015, China

${ }^{2}$ Guanlu Construction Co,. LTD, Linyi 273300,China

wangxq@zucc.edu.cn, bcuiy@zucc.edu.cn, czhangsm@zucc.edu.cn, d912494286@qq.com

${ }^{*}$ Corresponding author

Keywords: Foundation, Soft and Hard Soil Layers, Drainage Prestressed Pipe Pile.

\begin{abstract}
The soft soil foundation is widely distributed in our country, with the features of high moisture content, high compressibility, low strength and poor water permeability, among which the geological condition of alternate soft and hard soil layers is also common, and the constructions built on such foundation always encounter the problems of excessive total subsidence volume, obvious subsidence difference, later subsidence beyond limits, and inadequate carrying capacity, which would affect the normal use and safety of the constructions. Therefore, this paper developed an innovative construction technology of drainage prestressed pipe pile for foundation composed of alternate soft and hard soil layers, and introduced the process principles, scope of application, technical features, process flow and operating points of the technology.
\end{abstract}

\section{Introduction}

Due to the features of high moisture content, low shear strength and poor carrying capacity of soft soil, the constructions built in the soft soil region always have the problems as big setting volume, poor stability, and uneven subsidence. Therefore, a lot of domestic and overseas experts and scholars have done a lot of research on the treatment technology of soft soil foundation. Xing Haofeng[1] et al. verified the rationality and feasibility of simplified analysis on the drainage system of longboard-short pile composite foundation via finite element method and engineering practice. Tang Tongzhi[2] et al. studied the drainage consolidation properties of concrete core - gravel pile composite foundation, and the results suggested that concrete core - gravel pile structure could accelerate the dissipation of excess pore water pressure, facilitate the consolidation and compactness of foundation soil between piles within the scope of pile length. Du Guangyin[3] et al. measured the intensity change of foundation soil between piles after the construction of drainage cement injection pile via the methods of static cone penetration test and four-bladed vane shear, and the results showed that the intensity decreased first, then increased along with the age of pile.

However, there is no much study on the foundation composed of alternate soft and hard soil layers. Chen Xia[4] et al. used PLAXIS to simulate the construction process of dual-layer foundation under different parameters, analyzed the change rule of foundation composed of alternate soft and hard soil layers, studied the mechanics characteristic of hard crust with reciprocal theorem and made numerical calculation, developed a set of feasible calculation method. Wang Liangqing[5] et al. conducted field bearing plate test to measure the elastic modulus of rock mass composed of alternate soft and hard soil layers, used ANSYS to make computer simulation of triaxial compression test of composite stratified rock mass, drew the conclusion that the equivalent elastic modulus of composite stratified rock mass on the parallel level and vertical level are 2.57 3.93 MPa and 0.48 2.99 MPa.

This paper made an innovation on the traditional treatment method of foundation composed of alternate soft and hard soil layers, developed a construction technology of drainage prestressed pipe pile for foundation composed of alternate soft and hard soil layers, which has the advantages of good carrying capacity, subsidence reduction, acceleration of drainage and consolidation of the 
surrounding soil, low maintenance cost, and high performance-cost ratio. The technical principles, scope of application, technical features, construction process and operating points of the technology were introduced in this paper.

\section{Technical Principle \& Scope of Application}

(1) Technical principle

The precast pipe pile is fixed on the expanding precast pile toe, 3-4 series-connected curved steel plates are uniformly secured on the outer wall of the prestressed pipe pile at the elevation height of bearing board and drain board, the lower series-connected curved steel plates are fixed on 2-3 steel strands, and geo-bags are put on the expanding precast pile toe and outside the prestressed pipe pile, as shown in Figure 1. During the construction, rotary drilling rig is first used to remove dry soil to form hole, the pile body is lifted and pressed into the hole down to the designed depth using static pile press machine, pervious concrete is injected into the annular space formed by geo-bag and prestressed pipe pile through conduit, the steel strands are lifted at the same time to spread the curved steel plates to form bearing board and drain board, and finally the construction of cover board and the horizontal main drainage pipe is performed on the top of the cover board.

(2) Scope of Application

This technology is applicable for the treatment of foundation composed of alternate soft and hard soil layers in the highway, municipal works, airport, dam and other projects.

\section{Technical Features}

This technology owns the following features:

(1) The bearing board and the drainage board are made by the expanding-extrusion device on the top of hard soil layer and soft soil layer, which has good effect of improving the carrying capacity of pile, and accelerating the drainage and consolidation of the surrounding soil.

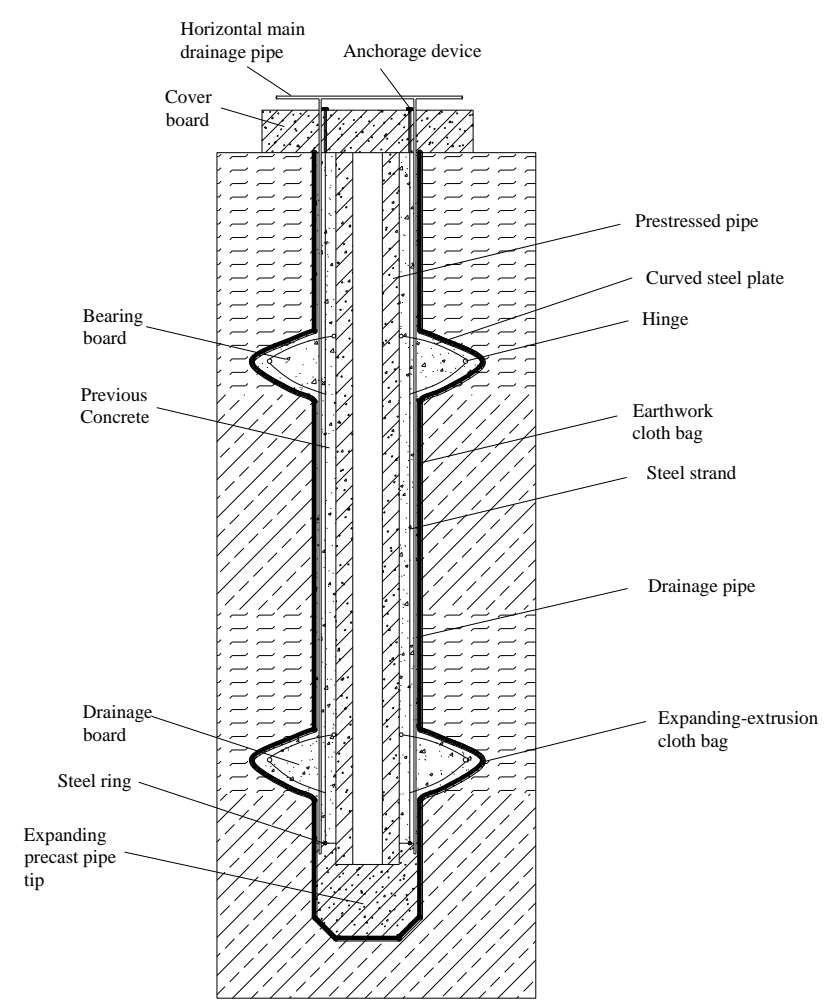

Fig. 1 Drainage Prestressed Pipe Pile

(2) The expanding-extrusion device is made of 2 series-connected curved steel plates. These curved steel plates are secured on the pre-imbedded part of the prestressed pipe pile via hinge, and 
the lower connected parts are welded on 2-3 steel strands. During the construction, while the steel strands are lifted, the curved steel plates are expanded to form bearing board or drainage board, which has the advantages of easy operation and good control of construction quality.

(3) The curved steel plates has the reinforcement effect, which could improve the shearing resistance of bearing board or drainage board, increase the strength and durability of the pipe pile.

\section{Process Flow and Operating Points}

(1) Materials

Choose roll-type geo-bag, with a weight per unit area of $230 \mathrm{~g} / \mathrm{m}^{2}$, an effective aperture within $0.07 \sim 0.5 \mathrm{~mm}$, a tear resistance greater than or equal to $0.9 \mathrm{kN}$, a permeability coefficient $\mathrm{K}=1 \times$ $10^{-2} \sim 1 \times 10^{-3} \mathrm{~cm} / \mathrm{s}$, a CBR burst strength greater than or equal to $5.5 \mathrm{kN}$.

(2) Operating points

1) Drilling and hole forming

Use rotary drilling rig to drill dry soil and form a hole, the working principle of which is to rotate partial blades of the screw sleeve on the rig rod to cut the soil layer, and make the soil into the sleeve, when drilling down to certain depth, lift the screw sleeve, clear the soil in it, then put it down again, work in this way repeatedly until drilling to the depth required.

2) Hoisting

After hoisting the prestressed pipe pile, slowly move one end of the pile to the pile driver. After the prestressed pipe pile is put in the right position of the pile driver, insert the expanding precast pile toe into the pile hole with a depth of 0.5-1.0 m, use two theodolites (on the direction of 90 degree intersection angle) to bilaterally control the perpendicularity of the pile.

3) Pile pressing

While applying static pressure method for construction, at the beginning stage of pile pressing, the velocity can' t be too fast, it should be selected according to the soil condition shown by the geologic report, generally at $2.0 \sim 3.0 \mathrm{~m} / \mathrm{min}$. For the first $2-3 \mathrm{~m}$ of pile pressing, the key point is to observe the pile body, the perpendicularity of the rack should be controlled at the first section of pile, and the deviation should not exceed $0.5 \%$ of the pile length. When going down to certain depth, the pile body is stable and the perpendicularity is adjusted in a bidirectional way by the theodolite to be correct, sink the pile by normal settling distance. During the process of pile pressing, we should always observe whether the pile has displacement or deviation, and make the record.

4) Pile connection

Stop pile pressing when the pile head of the first section of pile is pressed down to $0.5-1.0 \mathrm{~m}$ away from the ground, and start the pile connection work. Before pile connection, the connection of geo-bag, conduit and drainage pile should be done first, the geo-bag could be connected by sewing, and the conduit and the drainage pile could be connected by special joint. During the pile connection, first remove the rust and mud at the two ends of the pile, and then align the bottom end of the pile. After aligning the upper and the lower section end plates and preliminarily adjusting the perpendicularity, make spot welding at 4-6 points around the groove by manual arc welding, then adjust the perpendicularity again.

5) Pressure concrete injection

Use pressure pump to inject pervious concrete into the annular space through two conduits, and keep lifting the conduits.

When pressure injecting pervious concrete into the expanding-extrusion cloth bag, lift the steel strands to make the curved steel plate expand, and form bearing board or drainage board. The external diameter of bearing board or drainage board is $1000 \sim 1500 \mathrm{~mm}$.

6) Cover board construction

When the pile body reaches certain strength, perform pouring construction of cover board. Adopt pervious reinforced concrete cover board with a diameter of 1000-1200 mm and thickness of 200 $\mathrm{mm}$. The hole for steel strands is premade on the cover board, and built-in PVC piles with a diameter of $30 \mathrm{~mm}$ can be used. 


\section{Summary}

We drew the following conclusions via the field construction of prestressed pipe pile and measured data:

(1) When applying this technology, curved steel plates placed in the bearing board and drainage board provide the effect of reinforcement, and there is drainage pipe in the pile, which could draw water during the construction, thus this technology could improve the carrying capacity of pile, shorten the drainage consolidation cycle of the surrounding soil, control the foundation subsidence within the construction period.

(2) When applying this technology, during the entire construction process the work field is broad, which is easy for management; and the method of drilling dry soil for forming holes avoids mud contamination, able to guarantee good surrounding environment, provide environmental protection.

\section{Acknowledgement}

This material is based upon work funded by Zhejiang Provincial Natural Science Foundation of China under Grant No.LQ12E09002; Project(51308497)supported by National Natural Science Foundation of China.

\section{References}

[1]H.F. XING, Z. ZHANG, G.B. YE, etc. Simplified Analysis for Drainage System of Composite Foundation Improved by Cement mixing Columns and Vertical Drains, J. Journal of TONGJI university (Natural Science). 2011, 39(5) 656-660.

[2]B.Z.TANG, R.W. WANG, J.B.YIN, etc. Drainage Consolidation Characteristics and Experimental Study of Concrete Core Gravel Pile Composite Foundation, J. Highway. 2008 (12) 4-8.

[3]G.Y. DU, Y.K. WU, S.Y. LIU. Effects on the strength of soft soils surrounding piles in drain and dry jet mixing column methods, J. Journal of Engineering Geology. 2006, 14(1) 122-126.

[4]X. CHEN. Study on deformation characteristics of two-layered soil foundation, D. Yanshan University. 2013.

[5]L.Q. WANG, Y. LIANG, L. FAN, etc. Experimental Study on Elastic Modulus of Soft and Hard Interbedded Rockmass of the Yujianhe Reservoir Arch Dam Foundation in Guizhou, J. Geological Science and Technology Information. 2010, 29(4). 